\title{
Salud y paisaje \\ contribución desde el termalismo a la revitalización de zonas rurales (el caso de Pozo Amargo, Cuenca Del Guadaira, España) ${ }^{*}$
}

\author{
Health and landscape \\ a contribution to the renew of rural lands (the case \\ of Pozo Amargo, Cuenca Del Guadaira, España) ${ }^{* *}$
}

\author{
JESÚS RAÚl NAVARRO GARCÍA \\ Escuela de Estudios Hispanoamericanos \\ Consejo Superior de Investigaciones Científicas (CSIC) \\ C/ Alfonso XII, 16 \\ 41002 Sevilla. Espanha. 954501120 \\ jrauleeha@hotmail.com
}

RESUMEN Ubicado en la contaminada cuenca del río Guadaíra (Andalucía, España) el balneario de Pozo Amargo es una buena muestra del rico patrimonio arquitectónico vinculado al agua que han generado sus habitantes a lo largo de estos últimos siglos. Este patrimonio ha experimentado un abandono similar al del propio río pero tanto el movimiento ciudadano como la respuesta de la administración han permitido paliar ambas situaciones. Hoy en día, la rehabilitación del antiguo balneario puede suponer una interesante iniciativa que aúne la mejora ambiental y paisajística del alto Guadaíra con la recuperación del patrimonio artístico y etnográfico de la zona, así como la puesta en marcha de una experiencia pionera de proyecto paisajístico aplicado a destinos turísticos de salud capaz de generar riqueza en la zona.

* Artigo recebido em 08/08/2011. Autor convidado.

** Una primera versión oral de este trabajo fue presentada en el VII Congreso lbérico sobre gestión y planificación del agua, celebrado en Talavera de la Reina, Toledo, del 16 al 19 de febrero de 2011. Se enmarca dentro de las actividades científicas desarrolladas en el proyecto de excelencia "Andalucía-América Latina: intercambios y transferencias culturales" (HUM 03215), de la Consejería de Innovación, Ciencia y Empresa (Junta de Andalucía). 
Palabras-clave saúde, paisagem, águas termais

ABSTRACT Located in the polluted basin of Guadaira's river (Andalusia, Spain), the Pozo Amargo's spa is a good example of a rich architectonical heritage related to water that inhabitants have created over the last few centuries. This heritage has suffered a similar degradation to the river, but both the citizen's movement and the Administration's response have made possible the mitigation of both situations. Nowadays, the restoration of the former spa can be an exciting initiative that joins the environmental improvements and the landscape value of the Alto Guadaira's with the recovery of artistic and ethnographic heritage of this area. Moreover, it will make possible the launching of a pioneering experience of a landscape's project applied to touristic and health destinations that can generate wealth in the area.

Keywords health, landscape, thermal spring

\section{Introducción}

Las villas termales han sido enclaves que han gozado habitualmente de una gran belleza natural y paisajística, circunstancia que no pasó desapercibida para usuarios y viajeros que, atraídos por las cualidades de las aguas y también de sus paisajes, se acercaron a estos lugares para encontrar alivio a sus enfermedades y achaques. ${ }^{1}$

Partiendo de la importancia que el Convenio Europeo del Paisaje da al paisaje como elemento que contribuye a incrementar la calidad de vida de los ciudadanos, nuestro trabajo pretende abordar cómo desde el siglo XVIII ya el paisaje contribuyó a incrementar la fama de las calidades de las aguas mineromedicinales y cómo la contemplación y disfrute del mismo constituía una de las más habituales actividades de los bañistas. ${ }^{2}$ En este sentido, conectar la recuperación de un antiguo balneario con un plan de gestión y ordenación paisajística de su entorno tiene una lógica evidente. Nos parece muy conveniente integrar las políticas de paisaje en las políticas de desarrollo rural que impulsen el termalismo dada la importancia del paisaje como elemento destacado de la calidad de vida de las poblaciones y de

1 Así, por ejemplo, es habitual que en obras dedicadas a los balnearios haya un primer capítulo dedicado al paisaje del lugar: SANTOS, Lorenço Calavia. Joyas de Aragón. Reseñas históricas de Jaraba, de sus afamados baños y de su milagrosa Virgen. Calatayud: Tipolit. de Guillén y Romero, 1918.

2 Una de las actividades más frecuentes en los balnearios es la contemplación del paisaje desde las carreteras próximas a los balnearios, desde las habitaciones de los hoteles, desde las alamedas, desde los bancos de descanso... El río, los jardines y las montañas cobran vida desde ellos: "Paralela a los soportales, corre una alameda sombría, con bancos en que los bañistas, cansados de pasear a la mañana el agua, reposan un momento. Pomposos matorrales de hortensias la adornan de trecho en trecho, y abajo, el río eterno de aguas inmobles, espejea las techumbres rojas y la silueta de las montañas". AZORín. Veraneo sentimental. Zaragoza: Librería General, 1929, p.23, 27-28. 
su bienestar físico-mental-espiritual. Esta importancia adquiere una mayor relevancia si cabe en destinos turísticos de salud como los del turismo termal.

Los paisajes poseen una capacidad restauradora para el ser humano más que evidente. No obstante, no hemos podido fijar aún qué tipo de paisaje posee una mayor capacidad restauradora. Algunos apuntan a que son los paisajes naturales (teoría de la restauración atencional) los que nos aportan con su contemplación una mayor sensación de bienestar, otros autores vinculan la capacidad de restauración con los paisajes en los que se refleja el desarrollo histórico-cultural que los ha creado, otros con aquellos paisajes que están vinculados a actividades de ocio y, finalmente, otros autores vinculan la capacidad de restauración con los paisajes que facilitan la relajación y la posibilidad de encontrarnos a nosotros mismos. En función de todos estos criterios podemos afirmar que pocos paisajes pueden alcanzar mayores capacidades de restauración que los termales si consideramos su ubicación en entornos naturales privilegiados, su rico patrimonio históricoarquitectónico, su vinculación tradicional a actividades de ocio y el cuidado que desde el siglo XVIII se ha tenido de que los espacios termales tuvieran unas condiciones que facilitaran el descanso y la recuperación anímica de los bañistas. El paisaje que rodea a las instalaciones balnearias no es por tanto algo simplemente estético, incorpora toda una vertiente cultural que es capaz de generar mucho más que simples emociones de bienestar. A ello ha contribuido también, sin duda, la construcción social que se ha realizado desde la antigüedad sobre la capacidad restauradora de los paisajes termales a través de las obras de escritores, cineastas y viajeros o las propias memorias escritas por los médicos. ${ }^{3}$ Las villas termales atesoran patrimonio cultural, calidad paisajística, entornos naturales y una concepción integral y moderna del término de salud.

La construcción de las grandes instalaciones balnearias en nuestro país, de los edificios complementarios y de los jardines que las suelen acompañar contribuye a crear un espacio apropiado para cualquier terapia vinculada al relax y al descanso, incorporando, en lo que podemos llamar coloquialmente paisajes naturales y rurales, elementos paisajísticos urbanos - si queremos incluso hasta artificiales -, que responden a la necesaria adecuación del entorno físico para poder prestar los servicios médicos,

3 En este papel ha destacado la literatura con autores como José Luis Sampedro (El río que nos lleva), Teresa Viejo (La memoria del agua), Manuel Vázquez Montalván (El balneario), Pardo Bazán (Un viaje de novios), Pío Baroja (Desde la última vuelta del camino), Benito Pérez Galdós (La de Bringas, La familia de León Roch, Fisonomías sociales), José María de Pereda (Sotileza, Nubes de estío, Los de Becerril), Manuel Vicent (El león de ojos verdes), Armando Palacio Valdés (La hermana San Sulpicio), Fernando Schwartz (Vichy, 1940), Azorín (Veraneo sentimental), Carmen Martín Gaite (El balneario), o Thomas Mann, Dostoyewski o Henrik Ibsen, entre otros muchos, así como el mundo cinematográfico con directores como Berlanga (Los jueves milagro), Fellini (8 y medio), Gorris (La defensa Luzhin), Resnais (El año pasado en Marienbad), Mikhalkov (Ojos negros), Nieto Zas (La perrera), Altman (Tres mujeres), Birkina (Secreto en llamas), Charles Chaplin (Charlot en el balneario) o el francés Jacques Tati. No menor debió ser el papel desempeñado por las escuelas de paisajistas gallegos o catalanes, que tuvieron una gran influencia en la creación del sentimiento nacional a través de la arquitectura termal. 
aunque introduciendo simultáneamente elementos naturales como los jardines en torno al agua, transformada en el elemento primordial de la configuración del paisaje termal. Estas instalaciones debían ser capaces de hacer plantear a sus usuarios una utopía posible en la que el paisaje tuviera una gran importancia para que dicho entorno termal adquiriera su dimensión utópica. Una dimensión utópica que, en parte, poseen. Sobre todo aquellas villas termales de referencia especialmente vinculadas a la cultura local desde el ámbito paisajístico, pero no sólo desde este ámbito. ${ }^{4}$ Por tanto, en las villas termales esa comunicación entre entornos físicos, fundamentalmente rurales y marcados por la naturaleza, y urbanos (pequeñas poblaciones más el complejo termal) debe estar marcada por la armonía del resultado final: unos paisajes mixtos en los que la naturaleza se urbaniza y se vuelve a naturalizar dando como resultado villas termales de enorme riqueza paisajista potencial. La planificación urbanística en estas hermosas villas termales debe ser respetuosa, no sólo con el inmenso patrimonio que atesoran, tanto desde el punto de vista hidrológico como arquitectónico y paisajístico, sino también respetuosa con los miles de bañistas que acuden a ellas por la calidad de sus aguas y por las cualidades del entorno natural y cultural que contribuyen a incrementar su calidad de vida y su estado de bienestar. ${ }^{5}$ Esta interactuación que algunos autores han señalado entre el entorno activo y el pasivo es la base de nuestra propuesta, muy en consonancia también con las nuevas tendencias en salud que recomiendan considerar los hábitos y los estilos de vida al hablar de la salud de los ciudadanos. En este nuevo concepto de salud que define la OMS se inserta claramente la oferta de las villas termales, enlazando con una dilatadísima trayectoria que aúna patrimonio cultural, calidad paisajística y concepción integral y moderna del concepto de salud, que tiene mucho que ver con el concepto de la armonía filosófica, social y ecológica entre el hombre y el paisaje ${ }^{6}$ como ya presagiara en el siglo XIX el gran geógrafo anarquista Élisée Reclus a lo largo y ancho de su extensísima obra.

\section{La cuenca del Guadaíra y Pozo Amargo}

La cuenca del Guadaíra ha sido desde hace muchos años foco de constantes protestas y reivindicaciones sociales motivadas por la intensa

4 LUGINBÜHL, Yves. Paisatge i benestar individual i social. In: Paisatge i salud. Barcelona-Olot: Observatori del Paisatge-Generalitat de Catalunya, 2008.

5 Marco teórico para analizar las relaciones entre paisaje natural, salud y calidad de vida. Ponencia presentada a la mesa redonda Urbanismo, paisaje y salud pública. ESTRADA, Eduardo Moyano y CANALES, Carlos Priego Gonzáles de. XIII Congreso de la Sociedad Española de Salud Pública y Administración Sanitaria. Sevilla, 3-6 de marzo de 2009.

6 DURAND, Asher B. Cartas sobre pintura de paisaje (1855). Madrid: Fundación Juan March, 2010; BEDELL, Rebecca. La Naturaleza es un gran remedio: Durand y el paisaje terapéutico. Los paisajes americanos de Asher B. Durand (1796-1886). Madrid/New York: Fundación Juan March/Historical Society, 2010, p.192-201. 
contaminación de sus aguas y por el abandono de su riquísimo patrimonio cultural vinculado al agua. Los planes que la administración ha puesto en marcha en la cuenca baja y media del río (centrados en las ciudades de Alcalá de Guadaira y Morón especialmente) han paliado en cierta forma estos problemas pero la cuenca alta del río, ${ }^{7}$ deshabitada y sin los problemas antes citados, ha quedado fuera de estas políticas proteccionistas pese a su rico patrimonio natural y cultural, digno de protegerse y darse a conocer antes de su degradación. Dentro de esta cuenca alta del río Guadaira se conserva un interesante enclave termal: el de Pozo Amargo, que constituye el caso más interesante del urbanismo balneario de la provincia de Sevilla a lo largo de su historia (aunque hoy pertenezca a la provincia de Cádiz). ${ }^{8}$ A partir de la gran importancia que tiene la integración del agua termal como recurso en el sistema productivo local estudiaremos de que forma la recuperación del balneario puede ayudar a conservar el patrimonio cultural y natural del territorio del alto Guadaira. ${ }^{9}$ No se nos oculta que al plantear la reapertura de un manantial de aguas mineromedicinales debemos integrar las políticas paisajísticas con las ambientales para poder conservar las potencialidades del agua como motor de recuperación económica y devolver a Pozo Amargo sus señas de identidad como villa termal y a la cuenca su papel histórico de proveedora de aguas de calidad al área metropolitana de Sevilla, su conexión simbólica con el agua y el carácter identitario que, sin duda, posee.

Actualmente estamos trabajando en la propuesta de un plan de actuación en el poblado de Pozo Amargo y su entorno. A partir de su puesta en valor como ejemplo de arquitectura tradicional de la zona y de la reapertura de la explotación de sus aguas mineromedicinales, se tratará de ver la conveniencia de preservar lo que queda del poblado así como de proteger la arquitectura rural tradicional en sus proximidades, unas cercanas explotaciones salinas, el patrimonio arqueológico y el entorno paisajístico de la sierra y cuenca alta del Guadaira, así como el propio manantial de aguas mineromedicinales. En definitiva, se pretende recuperar y revalorizar el destacable patrimonio histórico, hidrogeológico, sociocultural y artístico que

7 Programa coordinado para la recuperación y mejora del río Guadaira, Agencia Andaluza del Agua, Consejería de Medio Ambiente: http://www.rioguadaira.es/mapsite2/index.php?content=2\# (capturado el 23 de febrero de 2011); Programa coordinado de recuperación y mejora del río Guadaira. Sevilla: Consejería de Obras Públicas y Transportes, Junta de Andalucía, 1999; ORDÓNEEZ, Joaquín. El Guadaíra: un plan que nunca llega. La restauración de la Cuenca del Guadalquivir. Aportar ideas para construir realidades. Madrid: Confederación Hidrográfica del Guadalquivir-Ministerio de Medio Ambiente, p.111-118, s.f. La calidad del agua ha sido la preocupación fundamental como puede apreciarse en http://www.rioguadaira.es/blogsite/calidad/calidad2.htm (capturado el 23 de febrero de 2011). La contaminación de la industria de la aceituna de mesa de Morón de la Frontera. Morón de la Frontera, Centro de Estudios Caleros, diciembre de 2008; La industrialización medioambientalmente sostenible de la aceituna de mesa. I Jornadas Internacionales de la Aceituna de mesa. Sevilla, marzo 2006.

8 ROMERO, José Reina. Balneario de Pozo Amargo (Documento I). Morón de la Frontera: Asociación Cultura Amigos de Morón, 1993; ROMERO, José Reina. Balneario de Pozo Amargo (Documento II). Morón de la Frontera: Asociación Cultural Amigos de Morón y Asociación "Los Baños" de Pozo Amargo, 1994.

9 BLÁZQUEZ, Florentino Pozo. Patrimonio histórico en el ámbito rural de la cuenca del río Guadaíra. Sevilla: Consejería de Obras Públicas y Transportes, 2000. 
rodea estos entornos privilegiados que son los antiguos balnearios como espacios vinculados a la salud, la tranquilidad y el disfrute del paisaje. ${ }^{10}$

Indudablemente, Pozo Amargo se enmarca en la trayectoria histórica y urbanística general que siguieron los balnearios en España desde la antigüedad clásica como lugares vinculados a la salud, a la higiene y a la socialización, así como a proyectos arquitectónicos y urbanísticos. ${ }^{11}$ De las termas clásicas se pasó a un concepto mucho más moderno de balneario que arranca en España con la ilustración y el avance de las teorías higienistas del siglo XIX. ${ }^{12}$ De hecho, es a fines del siglo XVIII cuando se quiere construir el balneario en Pozo Amargo y, aunque se trata de un balneario pequeño, el proyecto de edificación es ya paralelo al de los grandes planes de actuación en viejos balnearios peninsulares como el de Trillo o Sacedón. Desde antiguo los balnearios fueron entendidos como ciudades ideales y por ello con la ilustración se trató de dotarlos aún más de modelos urbanísticos que facilitaran ante todo el bienestar de los agüistas. Una cierta preocupación por el paisaje y el entorno del balneario se fue abriendo paso como una terapia complementaria a la acción de las aguas. La utilización de estas instalaciones por la burguesía y la aristocracia obligó también, algo más tarde, en el siglo XIX sobre todo, a un mayor esmero en los cuidados urbanísticos, arquitectónicos y en la planificación de los espacios públicos, construyéndose ya instalaciones específicas (fuentes, parques, quioscos de música, casinos, etc.) cuya cantidad y calidad van a depender de la categoría del propio balneario. ${ }^{13}$ Pozo Amargo cobra vida en la Restauración monárquica, en ese mismo período en el que los balnearios españoles alcanzan también su época dorada. ${ }^{14}$

Nuestro trabajo pretende resaltar el importante bagaje socio-cultural que atesoran las instalaciones termales así como su fuerza dinamizadora del entorno rural que les rodea. ${ }^{15}$ En el caso de Pozo Amargo, estaríamos hablando de aprovechar un recurso hoy infrautilizado, el agua mineromedicinal, de recuperar y proteger el urbanismo del poblado termal y de que este lugar pudiera resolver algunos de los graves problemas que hoy le aquejan: entorno degradado por la pérdida de vegetación de ribera, paisajes adehesados en clara regresión por la expansión del cultivo del olivar y del

10 AMARO, María Asuncion Leboreiro. El balneario: la ciudad ensimismada. Vigo: Colegio Oficial de Arquitectos de Galicia, 1994.

11 MALISSARD, Alain. Los romanos y el água. Barcelona: editorial Herder, 2001

12 Entre la literatura abundantísima existente destaquemos por su calidad: ÁLVAREZ, Luis Alonso; TATO, Elvira Lindoso y RODRÍGUEZ, Margarita Vilar. O lecer das aguas. Historia dos balnearios de Galicia (1700-1936). Vigo: Galaxia, 2011; LARRINAGA, Carlos. Patrimonio del sector turístico: Ios balnearios. El caso guipuzcoano. Areas. Revista internacional de Ciencias Sociales, Madrid, n.29, p.91-101, 2010, y el excelente de RODRÍGUEZ-SÁNCHEZ, Juan Antonio. Historia de los balnearios de la provincia de Málaga. Málaga: Diputación Provincial de Málaga, 1994.

13 AMARO, María Asuncion Leboreiro. El balneario, p.101-163.

14 ROMERO, José Reina. Balneario de Pozo Amargo (Documento I), p.28-29.

15 VILLAR, Juan José Molina. Termalismo y turismo en Catalunya: un estudio geohistórico contemporáneo. Barcelona: Universidad de Barcelona, 2004 (Geografia, Tesis doctoral). 
cereal, patrimonio cultural y arqueológico escasamente valorado y difundido, empobrecimiento faunístico por la presión agrícola, falta de tratamiento de las aguas negras vertidas, etc. ${ }^{16} \mathrm{Abordar}$ un proyecto de rehabilitación paisajística del perímetro de protección de las aguas mineromedicinales y reabrir las instalaciones termales en un futuro no demasiado lejano contribuirían a preservar sin duda el rico patrimonio de la cuenca alta del río Guadaira y a crear una interesante experiencia de recuperación ambiental y paisajística en torno a los conceptos de agua, salud, paisaje y ocio. ${ }^{17}$

\section{Definición del ámbito territorial de la cuenca del Guadaíra}

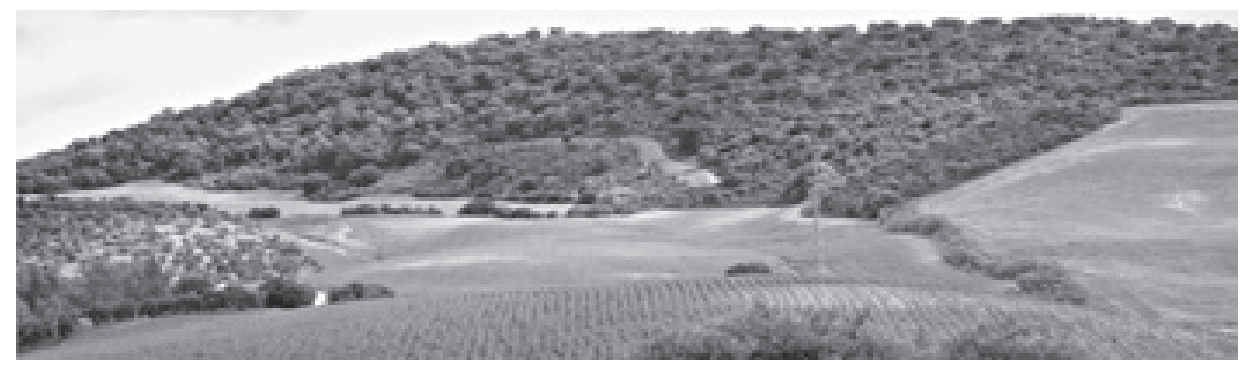

Imagen 1

La cuenca hidrográfica del río Guadaíra es una cuenca pequeña, delimitada por la depresión del Guadalquivir y por otra unidad geomorfológica: las Subbéticas. Tiene aproximadamente $1.305 \mathrm{~km}^{2}$, que se distribuyen a lo largo y ancho de 15 términos municipales en los que viven más de trescientas cincuenta mil personas. Es, fundamentalmente, una cuenca sevillana aunque, paradógicamente, la ubicación del antiguo balneario de Pozo Amargo se encuentre dentro del municipio gaditano de Puerto Serrano. ${ }^{18}$ La cuenca presenta una baja altitud, incluso en su cabecera, ya que el Guadaíra nace a tan solo 360 metros de altitud, en el piedemonte serrano. Esta circunstancia, unida a la cercanía del valle del Guadalquivir explica el corto recorrido del río, apenas $130 \mathrm{~km}$, en los que no hay ningún tipo de regulación. ${ }^{19} \mathrm{Su}$ cuenca está recorrida también por múltiples arroyos que actúan como afluentes, en especial por su vertiente derecha, aunque el más destacado

16 Programa de recuperación y mejora del río Guadaíra. Sevilla: Consejería de Obras Públicas y Transporte, 1999.

17 VARGAS, Remedios Larrubia, y GIL, Ana María Luque. Las estaciones termales en Andalucía: de la explotación tradicional a la configuración de un nuevo producto turístico integral. Cuadernos de Turismo, Murcia, n.10, p.101122, 2002.

18 REINA ROMERO, José. Balneario de Pozo Amargo (Documento I), p.34-39

19 No obstante, hubo una importante actuación en su tramo final que consistió en desviar su cauce original para evitar inundaciones en la ciudad de Sevilla. ITUARTE, Leandro del Moral. La obra hidráulica en la cuenca baja del Guadalquivir (siglos XVIII-XX). Gestión del agua y organización del territorio. Sevilla: Universidad de Sevilla-Consejería de Obras Públicas y Transportes/Ministerio de Agricultura, Pesca y Alimentación, 1991. 
de todos (el río Guadairilla) lo hace por su izquierda en sentido S-N como el propio Guadaíra. Dos hitos visuales debemos destacar también cuando recorremos la cuenca: por un lado, la sierra de Esparteros, ubicada en las proximidades de Morón de la Frontera, y por otro los Alcores, auténtico eje transversal que el Guadaira debe atravesar a la altura de Alcalá de Guadaira. La porosidad de este material terciario formado por calizas detríticas (calcarenitas) ha permitido la filtración de las aguas de lluvia y crear un manto freático importante y de calidad que históricamente ha permitido suministrar agua a la ciudad de Sevilla. Esta tradición de agua de primera calidad en la cuenca prácticamente ha desaparecido con los enormes problemas de contaminación que ha tenido el río y hoy en día la cuenca se abastece de agua procedente de otras cuencas, a excepción del pequeño poblado de Pozo Amargo. La recuperación del manantial para uso médico supondría, a nivel simbólico, recuperar la imagen del río y dignificarlo.

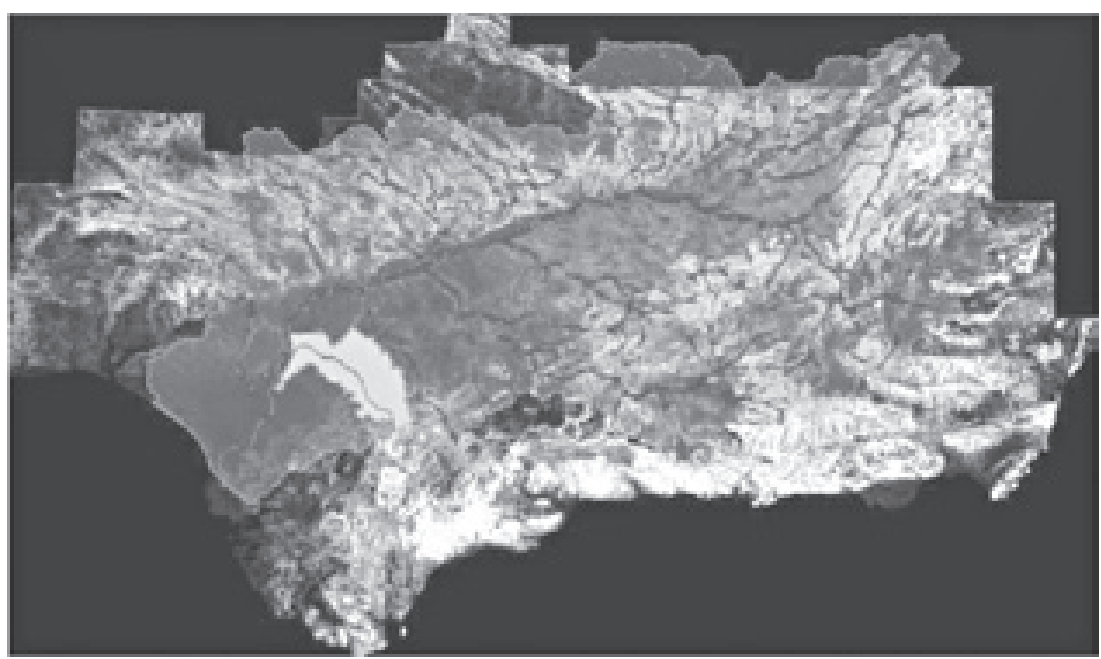

Imagen 2

La cuenca incluye varios tipos de paisajes según el Atlas de los Paisajes de España: marisma, área metropolitana de Sevilla, Ilanos interiores, campiña y, por último, los cerros y lomas del borde subbético, unidad en la que se ubica el balneario de Pozo Amargo. ${ }^{20}$ Un mayor acercamiento a la cuenca nos permitiría hablar de una pequeña zona de marismas en la nueva desembocadura del Guadaíra, remontando el río se abre paso otra zona de vegas y terrazas hasta llegar a la ciudad de Alcalá, luego una constituida por los relieves tabulares calcareníticos en toda la zona de

20 OLMO, Rafael Mata y HERRÁlZ, Concepción Sanz. (dirs.) Atlas de los paisajes de España. Madrid: Ministerio de Medio Ambiente y Medio Rural y Marino, 2010. 
Los Alcores (incluyendo en su término los municipios de Dos Hermanas, Alcalá, Mairena, El Viso y Carmona), más tarde la amplia zona rural de las campiñas acolinadas y alomadas dedicadas al cereal y al olivar cuyo centro geográfico estaría aproximadamente en la ciudad de Arahal y, finalmente, el piedemonte subbético, que empezaría a la altura de Morón y en el que se ubica Pozo Amargo. ${ }^{21}$

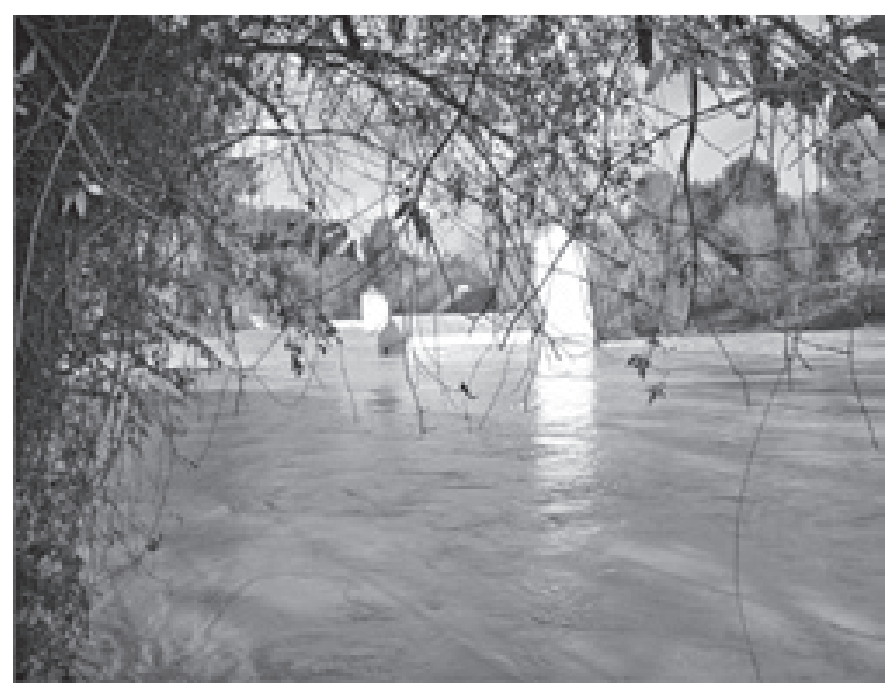

Imagen 3

Dentro de la cuenca tenemos que destacar el elevado índice de contaminación existente en sus aguas fluviales debido a los vertidos industriales, urbanos, de origen agrícola y, sobre todo, de los procedentes de la industria de transformación agrícola de la aceituna. A estos problemas de contaminación hídrica debemos añadir la importante degradación forestal, muy visible en las riberas de los ríos de la cuenca, en las dehesas y también en la campiña. Lejos de ocasionar en la población un alejamiento sentimental de su entorno, esta situación ha facilitado una fuerte capacidad de movilización, gracias a la cual se ha podido presionar a la administración autonómica andaluza para que afrontara la grave situación de la cuenca. Pese a su degradación, el río ha seguido viéndose no sólo como un factor destacado del patrimonio natural a conservar sino como la razón de ser de todo un riquísimo acervo patrimonial histórico y cultural: el Guadaíra es por tanto un elemento territorial de enorme trascendencia.

21 Mapa de los paisajes de Andalucía, en http://www.paisajeyterritorio.es/index.php/es/paisajes-de-andalucia/mapade-paisaje.html (capturado el 23 de febrero de 2011). Establece una clasificación en categorías, áreas y ámbitos paisajísticos. 
Los molinos hidráulicos que molían el trigo de sus campos a orillas del río tuvieron mucho que ver con la importancia adquirida por poblaciones como Alcalá en el suministro a la ciudad de Sevilla. Las explotaciones agrícolas de cereal y olivos ${ }^{22}$ alentaron la construcción de cortijos y haciendas en toda la cuenca suministrando materia prima a toda el área metropolitana e incrementando, de paso, su rico patrimonio arquitectónico. Pero la importancia del río no sólo fue económica y patrimonial. ${ }^{23}$ Antes de su deterioro, el Guadaíra fue un río identificado con el disfrute de sus orillas, sus parques y jardines, fenómeno lúdico-festivo-cultural alentado y propiciado por la Exposición de 1929 primero y más tarde por la llegada del ferrocarril hasta Alcalá. ${ }^{24}$ La recuperación del balneario de Pozo Amargo conecta por tanto con esa tradición de riqueza patrimonial (natural pero también históricocultural) que atesora toda la cuenca y también con la oferta lúdica que siempre ha generado el Guadaíra a los habitantes de la capital sevillana. Al papel histórico desempeñado en la cuenca por el cereal y la aceituna, como productos naturales procedentes del cultivo humano, añadiremos ahora el agua mineromedicinal natural como impulsora de la recuperación del río en su cuenca alta, no sólo desde la vertiente cultural y patrimonial que supone el balneario y poblado de Pozo Amargo sino también natural gracias al perfil paisajístico y medioambiental que pretendemos tenga el proyecto de recuperación del alto Guadaíra. El enfoque de cuenca que vamos a dar nos permite integrar aspectos físicos, humanos y culturales, también el ciclo del agua, en un marco que aporta sentido a las partes. Así, podemos hablar de una identidad de cuenca que contrasta con la realidad administrativa y que ha permitido conectar dos realidades muy distintas entre sí: el valle del Guadalquivir, por un lado, y los sistemas subbéticos, por otro. Esta conexión entre realidades geológicas muy diversas explica desde el propio afloramiento del agua a las características históricas, culturales y económicas del lugar.

Tanto la cuenca hidrográfica como el ciclo del agua nos pueden permitir conocer muchas de las paradojas que esconde el propio balneario dentro de su contexto. Unas paradojas que me asaltaron en cuanto me acerqué a la cuenca del Guadaíra. Nos encontramos en una cuenca históricamente

22 RAMOS, Guillermo Krumrain. El olivar en Morón: significación cultural, ecológica y económica. Mauror, Morón de la Frontera, n.10, p.73-97, primer semestre del 2001.

23 BLÁZQUEZ, Florentino Pozo. Patrimonio histórico en el ámbito rural de la cuenca del río Guadaíra; LERDO, Fernando Hidalgo de y CHAVES, Manuel Fernández. El entorno rural y el patrimonio histórico en Alcalá de Guadaira, siglos XIII-XX. Alcalá de Guadaíra: Ayuntamiento de Alcalá de Guadaira, 2006; BERNAL, Antonio Miguel. (dir.) Estudio de la industria panadera de Alcalá de Guadaira. Alcalá de Guadaíra: Ayuntamiento de Alcalá de Guadaira, 2003; DÍAZ, José Manuel Campos. El pan de Alcalá. Alcalá de Guadaíra: Ayuntamiento de Alcalá de Guadaira, 2005; BLÁZQUEZ, Florentino Pozo. Los molinos harineros de la cuenca del río Guadaira. Patrimonio histórico en el ámbito rural de la cuenca del río Guadaíra, p.377-393.

24 LACOMBA, Juan Fernández. La Escuela de Alcalá de Guadaira y el paisajismo sevillano, 1800-1936. Sevilla: Diputación de Sevilla y Ayuntamiento de Alcalá, 2002; RIVERO, Francisco García. Crónicas y memorias de Alcalá de Guadaira. Alcalá de Guadaira: Edición del autor, 2006. 
muy contaminada pero que sin embargo dispone de un manantial de agua mineromedicinal en Pozo Amargo. Es la primera paradoja. El poblado de Pozo Amargo, apenas sin población estable, es el único núcleo que se abastece con agua de la cuenca, el resto de las poblaciones han tenido que recurrir a agua procedente de otras cuencas debido a la mala gestión que se ha realizado de las aguas superficiales y subterráneas propias. En algún momento histórico se arrojó la toalla y el agua del Guadaíra, que abastecía a la capital sevillana con aguas de excelente calidad, se vio condenada a ser el desagüe natural de las industrias de envasado de las aceitunas de toda la cuenca (Morón, Alcalá de Guadaíra....). ${ }^{25}$ Segunda paradoja. Pozo Amargo, con su manantial de aguas mineromedicinales, es el único poblado que no depura, ni en el plano teórico ni práctico, sus aguas negras. ${ }^{26}$ Tercera paradoja. Resulta también enormemente llamativo que el alto Guadaíra, el territorio de la cuenca con mayor valor ambiental y paisajístico, y con las potencialidades patrimoniales que atesora, haya sido olvidado en los planes del Guadaíra blanco y verde. ${ }^{27}$ Cuarta paradoja. Y la última, con fuertes repercusiones en el enclave de Pozo Amargo, el desgajamiento administrativo de esta parte de la provincia de Sevilla a favor del término de Puerto Serrano, Cádiz, ha supuesto una grave interferencia en la identidad de cuenca en el alto Guadaíra.

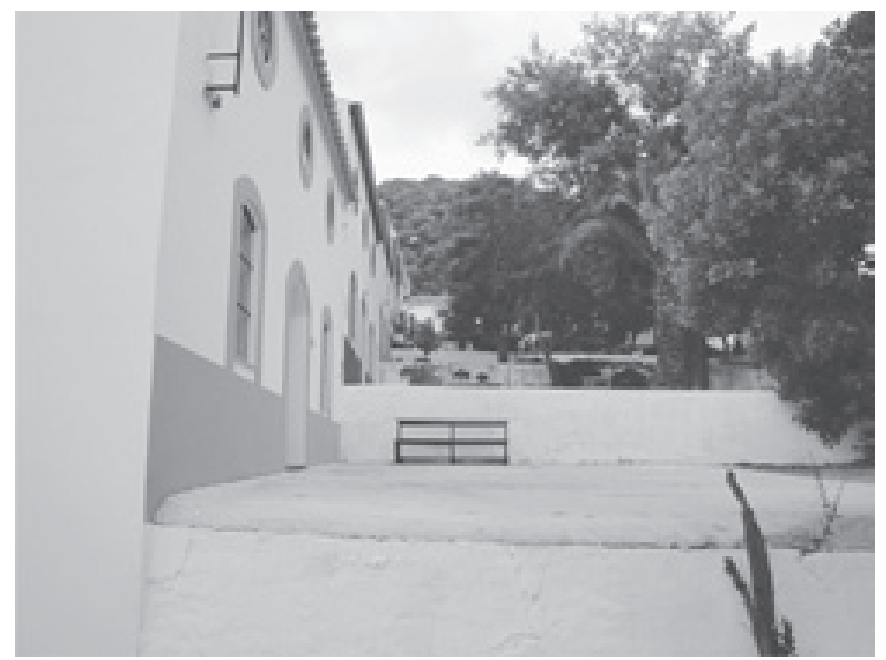

Imagen 4

25 ITUARTE, Leandro del Moral. (coord.) El sistema de abastecimiento de agua de Sevilla: análisis de situación y alternativas al embalse de Melonares. Nueva Cultura del agua, serie Informes, Bilbao, Kakeaz, n.5, 2ªed., 2002.

26 La depuradora de Pozo Amargo estuvo incluida dentro del plan denominado Guadaíra Blanco pero no se construyó.

27 ASOCIACÓN GAIA. Salvemos el Guadaíra entre todos. Plan Coordinado de Recuperación del río Guadaíra. Mauror, Morón de la Frontera, n.5, p.83-94, enero de 1998. 


\section{Caracterización hidrológica de la cuenca}

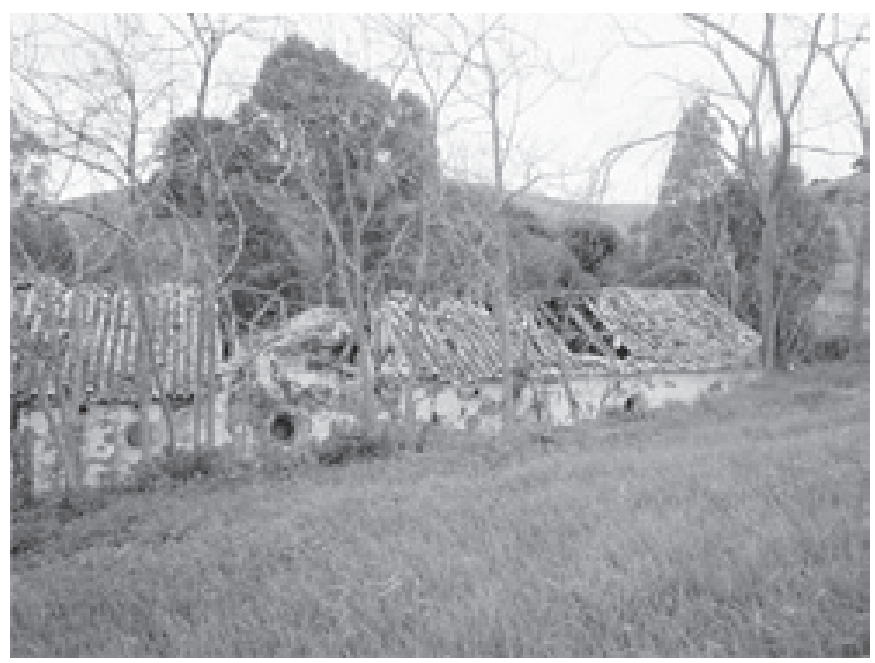

Imagen 5

La cuenca del Guadaíra supone una importante vía de conexión entre el valle del Guadalquivir, las Béticas y la cuenca Atlántica, circunstancia que incrementa el valor de la cabecera del río en donde se ubica el balneario y poblado de Pozo Amargo. ${ }^{28}$ Esta conexión con el Atlántico vinculó históricamente esta zona con el fenómeno del contrabando y también con el carlismo andaluz. El Guadaíra fue también un claro corredor de personas y mercancías hacia la capital del valle del Guadalquivir, Sevilla. Algo que deja bien claro su toponimia: río del abasto. Esta conexión entre valle del Guadalquivir, sierra y cuenca Atlántica favorece el tránsito, favorece también la aparición de patrimonio histórico-cultural y, en no pocas ocasiones, de conflictos. ${ }^{29}$ Los flujos han favorecido siempre a la cuenca baja, que coincide con el área metropolitana de Sevilla, pero la actuación en Pozo Amargo pretende cambiar esta tendencia y cobra sentido por ello.

Hidrológicamente hablando, mientras que el Guadaíra tiene una orientación S-N, el resto del sistema fluvial de la cuenca se caracteriza por una

28 ASOCIACIÓN GAYA. Inventario del paisaje natural del agua en Morón. I. El Alto de Guadaíra o río Esparteros (El arroyo del Fontanar y los embalses de Mancera y el Fontanar). Mauror, Morón de la Frontera, n.2, p.89-127, julio de 1996; MARTÍNEZ, Juan López. Primera aproximación a la pardilla en los ríos de la Sierra Sur Baja de Sevilla. Mauror, Morón de la Frontera, n.4, p.78-80, julio de 1997; SÁNCHEZ, Luis Rubiales. La nutria en el tramo alto del Guadaíra (Morón de la Frontera). Mauror, Morón de la Frontera, n.9, p.161-169, primer semestre del 2000.

29 Recordemos por ejemplo toda la historia de conflictos vinculada a la vecina banda morisca, sobre la que pueden mencionarse los trabajos de CALA, Juan Pablo Morilla. Tres fronteras defensivas en el Morón del siglo XV. Mauror, Morón de la Frontera, n.1, p.23-61, enero de 1996; V.AA. (coord.) Actas de las /l Jornadas de Temas Moronenses, 17 al 20 de octubre de 1994. Sevilla: Fundación Fernando Villalón y Departamento de Historia Medieval de la Universidad de Sevilla, 1996; RUIZ, M. A. Carmona. El aprovechamiento de la Algaida de Cote. (Bosque de San Pablo, Montellano). Siglos XIII-XVI, Mauror, Morón de la Frontera, n.9, p.3-17, primer semestre del 2000. 
orientación E-W en su margen derecha. Las margas y los yesos de la zona dan nombre a múltiples arroyos (Salado, Saladillo, Salado de Paradas, Salado de Mairena....) que se estructuran, debido a la naturaleza blanda de los suelos sedimentarios neógenos de origen marino, en una red dendrítica con alta salinidad. Por contra, en la margen izquierda hay muy pocos afluentes, aunque destaca el Guadairilla, que corre paralelo al Guadaira, y es el más importante de todos ellos. Estos cursos fluviales entallan el relieve acolinado predominante en la cuenca y las abundantes prácticas agrícolas suavizan más todavía el moldeado de las margas, yesos y arcillas.

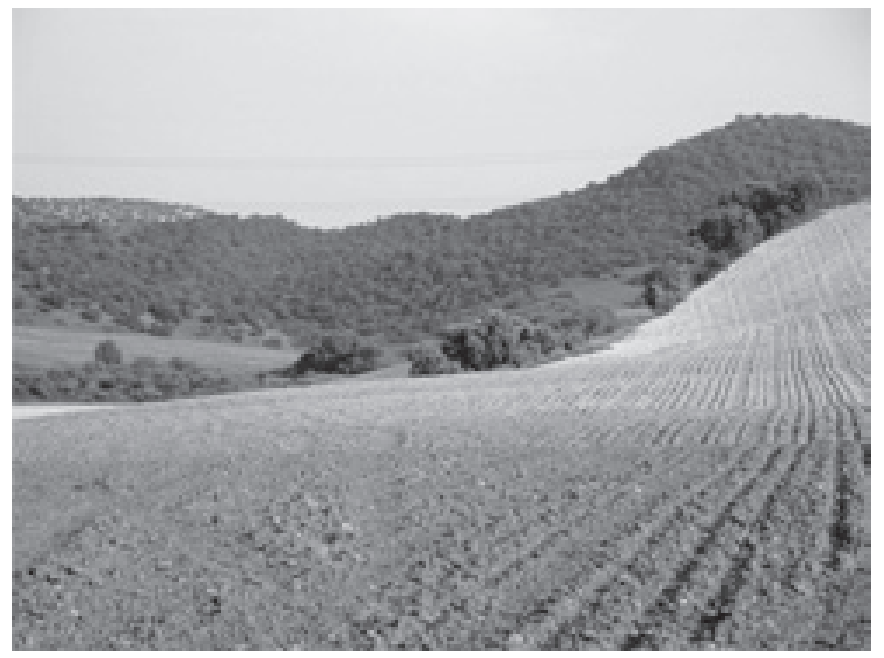

Imagen 6

La cuenca es rica en acuíferos, aunque estén hoy en día infrautilizados. El de Pozo Amargo es el menos relevante desde el ámbito cuantitativo aunque sí lo sea desde el cualitativo por la existencia del manantial que le da nombre. Paradógicamente, siempre ha abastecido al balneario y al poblado que creció a su lado. En la actualidad es el único enclave habitado que se abastece con agua de la cuenca del Guadaíra pese a los importantes acuíferos que ésta posee: ${ }^{30}$ Sevilla-Carmona $(1.150$ km²), Arahal-Paradas-Morón $\left(420 \mathrm{~km}^{2}\right)$ y el de la Sierra de Esparteros-Montellano $\left(11 \mathrm{~km}^{2}\right)$, con unas recargas anuales en torno a los doscientos $\mathrm{Hm}^{3}$, de los que apenas se utilizan para la agricultura cincuenta debido a que la cuenca destaca por tener una agricultura extensiva y de secano más que de regadío. ${ }^{31}$ El mayor consumo

30 Las poblaciones de la cuenca se abastecen de Emasesa, Aguas del Huesna y del Consorcio del Plan Écija, es decir, tienen tres gestiones diferentes y se nutren de recursos externos a la propia cuenca en los tres casos.

31 VALSERO, Juan José Durán. (coord.) Atlas hidrogeológico de la provincia de Sevilla. Madrid: Instituto Geológico y Minero de España, 2003; Programa de recuperación y mejora del río Guadaíra. Sevilla: Consejería de Obras Públicas y Transporte, 1999. 
urbano-industrial de agua en toda la cuenca se centra en la dinámica área metropolitana, no sólo por el consumo humano sino también por las necesidades de la industria, de los servicios y de la industria de transformación agrícola (Dos Hermanas y Alcalá de Guadaíra reúnen casi doscientos mil habitantes e importantes polígonos industriales y comerciales). La zona de la campiña presenta núcleos mucho más estancados, menos dinámicos, con poblaciones estabilizadas (Morón, Arahal y Paradas apenas superan los cincuenta mil habitantes entre los tres núcleos), aunque con elevado consumo de agua, caso de Morón de la Frontera. ${ }^{32}$ Morón es un importante foco de transformación agrícola (envasado de aceituna) que provocó desde los años noventa repercusiones medioambientales muy graves en el río, obligando a la administración a crear el Programa Coordinado de Recuperación y Mejora del Guadaíra, que incluía un plan de medidas eficaces como la construcción de balsas de vertidos y varias EDAR, así como un incremento del control sobre los efluentes industriales. Sólo el curso del Guadaíra que transcurre por el área rural del piedemonte subbético - en donde se ubica como sabemos Pozo Amargo - presenta un relativo buen estado en la calidad de sus aguas al tiempo que dicha zona apenas tiene consumo humano de agua por la escasa población que reside en ella. La escasa utilización porcentual de las aguas subterráneas - que no en números absolutos - para uso humano, agrícola e industrial, la mala calidad de la superficial y la no regulación del río favorecen el balance deficitario de la cuenca y obligan a utilizar recursos externos.

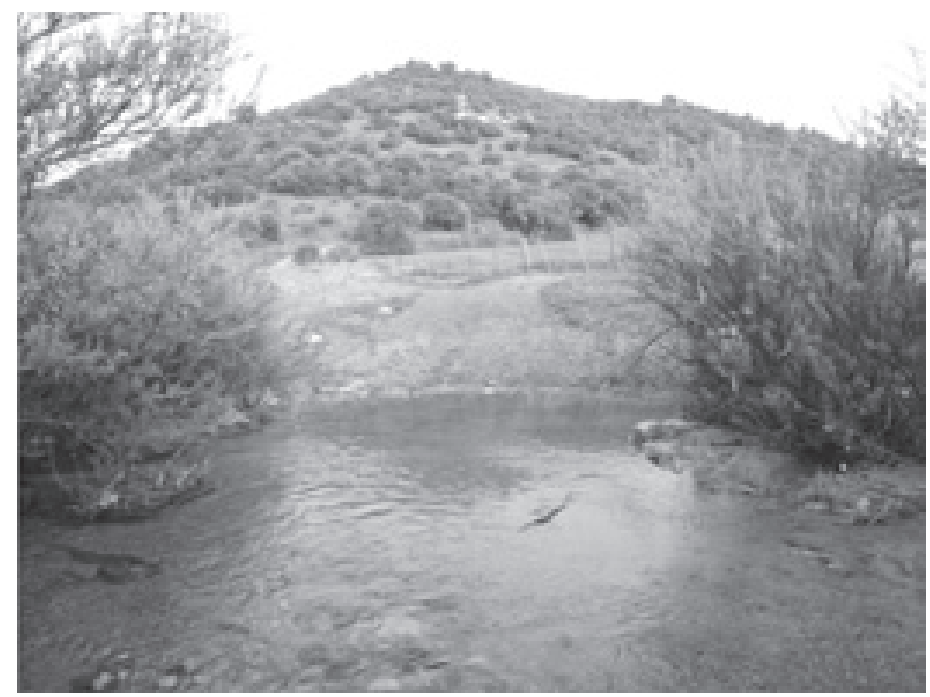

Imagen 7

32 Programa de recuperación y mejora del río Guadaíra. 
El mal estado general del agua en la cuenca se ve acompañado de graves deficiencias en los ecosistemas riparios (falta de vegetación que imposibilita la creación de galerías cerradas), en las dehesas (en claro retroceso, pese a que cubrían en el pasado toda la cuenca) y en los abundantes agrosistemas, que tienden al monocultivo de secano y al olivar en zonas poco propicias para su cultivo en ocasiones.

\section{Diagnóstico}

Al tratarse la cuenca del Guadaíra de un antiguo golfo marino colmatado de sedimentos calizos y calcareníticos - que han dado lugar a hitos paisajísticos como los Alcores y la sierra de Esparteros -, la geomorfología de la zona ha venido mediatizada por este hecho y por la evidente acción del agua, que no sólo ha intervenido en la modelación del relieve sino también en la formación de muchos acuíferos, actualmente recuperándose ya que el abastecimiento de agua de calidad para uso humano se hace desde otras cuencas como ya vimos. Por ello, la conservación del manantial de Pozo Amargo pasa necesariamente por una política general que preserve también las otras reservas de agua subterránea y por evitar a toda costa su contaminación. El acuífero de Pozo Amargo, a diferencia del resto de los acuíferos de la cuenca, no se ubica en su zona más poblada y, por tanto, difícilmente estará sometido a presión y sobreexplotación aunque podría llegar a verse afectado por la contaminación de las aguas negras del poblado y por la procedente del uso agrícola del suelo. Nuestro interés en preservar el agua subterránea de Pozo Amargo - y en general la de toda la cuenca - tiene su razón de ser: en todas las actuaciones sobre el Guadaíra se ha olvidado el estado de conservación de las aguas subterráneas y se ha centrado la actuación en la calidad química del agua superficial.

La conservación en la actualidad del poblado y del manantial de Pozo Amargo - aunque no de su balneario, abatido por el paso del tiempo -, nos permite hablar de que la expansión demográfica e industrial contenida hasta los años cincuenta del siglo pasado facilitó, en cierto modo, la conservación de los vestigios histórico-artísticos y antropológicos relacionados con el agua en la cuenca. Respecto a Pozo Amargo, el hecho de no estar próximo a grandes localidades ni a vías de comunicación muy frecuentadas también ha jugado a su favor, así como la circunstancia de haberse podido seguir utilizando las casas del poblado, tanto de primera como de segunda vivienda. De este modo, podemos afirmar que del rico patrimonio conservado en el Guadaíra es precisamente el del curso alto el único que mantiene su potencial funcionalidad, tanto en el caso del balneario como en el de las cercanas salinas tradicionales, aún en uso. Esto permite tener grandes esperanzas de que se conseguirá la conservación de estas ricas muestras del patrimonio histórico y etnográfico del lugar. 
Desde una perspectiva histórica, la transferencia del poblado de Pozo Amargo a la provincia de Cádiz no parece que haya sido una buena medida política pues supone romper la larga tradición que lo vinculaba a Sevilla, contribuyendo más si cabe a la sensación de abandono que tienen los vecinos de Pozo Amargo por parte de la administración local y provincial. ${ }^{33}$ Este hecho, sin embargo, ha fomentado el movimiento asociativo entre los propietarios de las viviendas del poblado, a quienes les une el sentimiento de residir en un lugar de especial valor patrimonial.

La recuperación del balneario y del paisaje de su entorno permitiría difundir las bondades de la cuenca alta del río Guadaíra, facilitar su acceso y dar a conocer la cabecera del Guadalete a través de la carretera que une Morón y Coripe. Trataría de llevarse al alto Guadaíra la faceta lúdica y también vinculada a la salud que en el pasado supuso la llegada del ferrocarril a Alcalá, acercando a los sevillanos un área de disfrute vinculada al agua mineromedicinal y al curso alto del río.

La actuación paisajística en el entorno del balneario pretende aliviar la homogeneización y el empobrecimiento de los ecosistemas vinculados al agua en toda la cuenca del Guadaíra debido a la presión humana. La recuperación de los bosques de ribera y de las márgenes del río, las herrizas, el matorral mediterráneo, los encinares y alcornocales, dará un valor añadido al entorno de Pozo Amargo. La expansión de las especies endémicas debe ir acompañada de un estricto control de especies invasoras, ornamentales y cañizos, de la recuperación de las poblaciones de anfibios, reptiles, aves asociadas a los cauces, aves esteparias (aguilucho cenizo, águila perdicera...), mamíferos (gamos, zorros, ginetas) y peces (anguila, barbos...). ${ }^{34}$

\section{Identificación de la actuación: poblado y balneario de Pozo Amar- go (Puerto Serrano, Cádiz)}

La actuación que proponemos se ubica en el Alto Guadaíra y se corresponde con la unidad paisajística del piedemonte Subbético y el área paisajística de la Sierra de Morón. Como ya hemos ido viendo, se trata de un ámbito rico en acuíferos, destacando por su proximidad el de Pozo Amargo, que da lugar al propio manantial, y el de Montellano. El acceso al poblado y antiguo balneario se realiza desde Sevilla-Morón a través de la carretera A8126, catalogada como carretera de interés paisajístico (Morón-

33 Este problema administrativo que conlleva la dependencia de Pozo Amargo de la provincia de Cádiz sólo puede solucionarse a través de una colaboración sincera y abierta entre dos municipios (Morón y Puerto Serrano), condenados a entenderse para tratar de ofrecer al alto Guadaíra una posibilidad de encontrarse a sí mismo y dignificarse. Antes de segregarse Pozo Amargo de Morón el propio Puerto Serrano se había segregado de la ciudad sevillana (1835), en BAREA, Joaquín Pascual. Origen del nombre y población de Arahal. Mauror, Morón de la Frontera, n.1, p.14, enero de 1996; ARCO, Sánchez del y CHEZO, D. Puerto Serrano entre el acta fundacional de 1820 y la exposición de 1887. Mauror, Morón de la Frontera, n.13, p.173-177, primer semestre 2004

34 Programa de recuperación y mejora del río Guadaíra. 
Algodonales), ${ }^{35}$ hallándose tan solo a 15 km de Morón de la Frontera. Se trata de un núcleo aislado de población que nació para acoger a los bañistas del cercano balneario. Al cerrarse este último, las viviendas del poblado fueron vendidas a particulares, quienes hoy en día las suelen utilizar como segunda residencia ${ }^{36}$ La historia de esta aldea nos acerca a otro aspecto íntimamente unido al termalismo como es la importancia de los manantiales de agua mineromedicinal para explicar el origen de poblaciones, como ya recogiera Plinio el Viejo o Séneca: Alhama de Granada, Alhama de Almería, Alhama de Murcia, Alhama de Aragón, Caldas de Malavella, Caldas de Montbui, Baños de Montemayor, Ourense...., ${ }^{37}$ todas ellas se vinculan a la existencia de aguas mineromedicinales en sus orígenes urbanos.

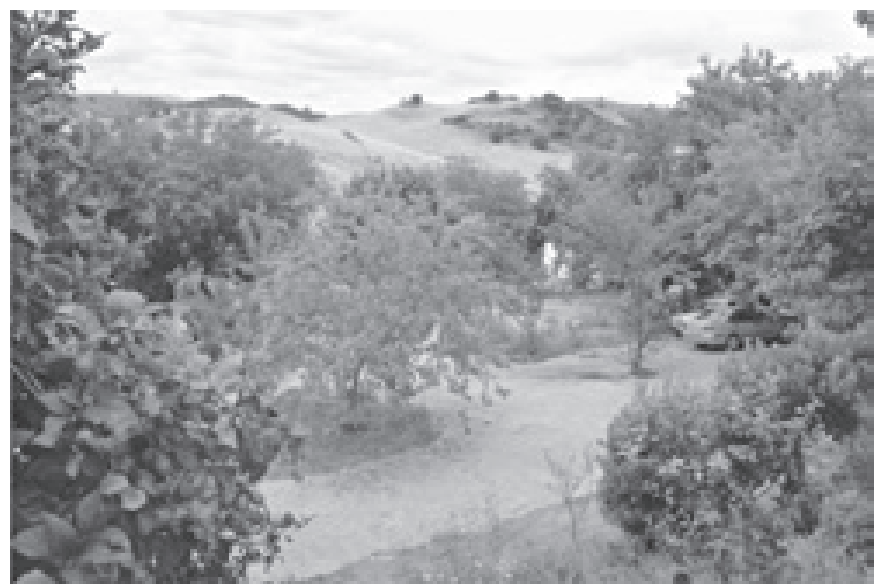

Imagen 8

El entorno del poblado está ocupado por zonas de monte y matorral mediterráneo (Sierra de Pozo Amargo y otras zonas, muy reducidas, de las sierras colindantes) y sobre todo por agrosistemas en los que hay dehesas, campos de cereal y olivar y explotaciones extensivas de reses. Hay por tanto una interesante muestra de ecosistemas que le aportan altos valores paisajísticos y naturales al lugar, que al mismo tiempo suponen fuertes potencialidades para el incremento del disfrute sensorial que llevaría aparejada la actuación en Pozo Amargo. ${ }^{38}$ Un disfrute sensorial que iría dirigido a la

35 Guía de carreteras Andalucía, Consejería de Obras Públicas y Vivienda, Junta de Andalucía, anejo VIII, en http:// www.juntadeandalucia.es/viviendayordenaciondelterritorio/www/jsp/guia carreteras/anejos.html (capturado el 23 de febrero de 2011).

36 ROMERO, José Reina. Balneario de Pozo Amargo (Documento II), p.39-42.

37 Estos establecimientos nada tenían que ver con las famosas termas de Caracalla o Diocleciano pues estas últimas utilizaban aguas que no eran mineromedicinales. Por tanto, los spa se puede decir que no son un invento moderno sino que también existían ya en la Roma clásica.

38 Aquí habría que mencionar los problemas que pueden derivarse del no tratamiento de las aguas negras de Pozo Amargo y de la contaminación procedente de los cultivos cercanos. 
obtención de mayores niveles de bienestar entre turistas y vecinos y a mejorar las características paisajísticas de la villa termal. Para ello se puede utilizar toda una serie de potencialidades sensoriales a través de una actuación como ésta en el ámbito rural. Ya en 1840 Madoz señalaba sobre Pozo Amargo que "La temperatura que se disfruta en este punto es agradable, principalmente en la primavera y estío, y los aires fríos, secos, ligeros, renovados y cargados de emanaciones aromáticas de los muchos vegetales que en él abundan". 39 El paseo, una de las actividades más vinculadas tradicionalmente a los balnearios se nos presenta para disfrutar de los sentidos: la vista, el olfato, el oído... adquieren su máxima expresión con esta actividad que puede convertirse en el silencio de la noche en una de las más gratificantes. Por eso las actuaciones ambientales y paisajísticas deben potenciar el uso de plantas autóctonas con aromas intensos, como el tomillo, la lavanda, la albahaca, la jara o los rosales silvestres ${ }^{40}$ en zonas ajardinadas pero también en las zonas recuperadas de bosque mediterráneo. ${ }^{41}$ En las zonas ajardinadas pueden utilizarse plantas ornamentales propias de la zona como el jazmín y la dama de noche de aromas exquisitos y frutales fragantes como los cítricos o las higueras, sin olvidar árboles de ribera como álamos y chopos que además de su cometido ambiental cubren funciones paisajísticas evidentes e inconfundibles marcando el serpentear del río. ${ }^{42}$ Todo ello recupera la calidad ambiental del entorno termal y mejora sus cualidades paisajísticas y potencialidades de restauración en el paseante y en el bañista. El propio Madoz ya señalaba también cómo estas cualidades estaban presentes en Pozo Amargo: "Por la parte E. y O. de la sierra hay dos profundos valles que forman grandes explanadas con algunas casas de cortijos, cómodas para pasear". ${ }^{43} Y$ eso desde hace varios siglos al menos, cuando el paseo se convirtió en la actividad por excelencia de la vida termal. ${ }^{44}$

La introducción de ganadería extensiva o de anfibios en el entorno de un balneario puede incrementar los sonidos capaces de absorber los

39 ROMERO, José Reina. Balneario de Pozo Amargo (Documento I), p.14.

40 Carmen Martín Gaite recrea un paseo nocturno lleno de sensaciones por los alrededores de un balneario: "No se oía ningún ruido en torno. Venía un aire limpio y suave, y, a rachas, un perfume pequeño a canela, a pan con azúcar; debía haber una mata de heliotropo allí cerca". GAITE, Carmen Martín. El balneario. Madrid: Alianza editorial, 1993, p.55.

41 PALMA, Manuel Díaz. Paseo botánico por la vía verde de la sierra. Mauror, Morón de la Frontera, n.6, p.121-128, julio de 1998.

42 ¿Cómo no recordar aquí aquellas maravillosas descripciones del librito de GIONO, Jean. El hombre que plantaba árboles? Barcelona: Duomo editorial, 2010: "Pero al regresar, pasando el caserío, vi correr agua por arroyos secos desde épocas inmemoriales (...) el viento dispersaba ciertas semillas. A la vez que reaparecía el agua resurgían sauces, mimbres, prados, jardines, flores y una razón de vivir" (he utilizado el cd con música de Paul Winter Consort y narración de Lara López, con traducción de Eloy Fuente, Sonifolk S.A., 1993). Algunas de estas medidas deben ir acompañadas de otras que restrinjan los malos olores procedentes de las futuras instalaciones, basuras, abonos, depuradora, etc. por lo que un estudio de los vientos predominantes se aconseja prioritario a la hora de fijar estos protocolos de calidad paisajística.

43 ROMERO, José Reina. Balneario de Pozo Amargo (Documento I), p.14.

44 Paradógicamente, no se ha avanzado mucho desde el siglo XIX pues aún hoy en día si revisamos algunas páginas web de instalaciones termales de lujo como la de Villa Padierna-Thermas de Carratraca nos llevamos la sorpresa de que un balneario como éste de nueve actividades propuestas a sus clientes, ocho están relacionadas con el paseo. 
ruidos molestos en un destino de turismo de salud y de bienestar, y puede funcionar como un mecanismo exitoso que se vislumbra en cierta forma en las descripciones de Azorín y que debía ser muy habitual en las instalaciones balnearias del s. XIX y principios del s. XX, caracterizadas - como la España de aquel momento - por una ruralidad mucho más intensa que ahora, por un mejor estado de los ríos y de los humedales ("El campo está silencioso, negro; se oye la nota cristalina de un sapo"). ${ }^{45}$ La proximidad del río Guadaíra al balneario permite jugar con su sonoridad, como ya señalara El Correo de Cantabria, del 14 de agosto de 1889, aludiendo a los valores paisajísticos y restauradores del río Pas: "La situacion de [balneario de] Punte Viesgo es agradabilísima prestándose a la tranquilidad del espíritu a que se contribuye la apacible corriente de las aguas del río". ${ }^{46}$

El susurro de las hojas, el del agua del río y de las fuentes, además de las posibilidades de contemplación, siguiendo la teoría de la restauración atencional, permiten la reflexión y la concentración, la disminución del estrés. Instrumentos todos ellos bien conocidos por los bañistas de dilatada trayectoria:

Todo respira paz y meditación y los constantes murmullos del río, que invitan a pensar en la permanencia del tiempo como presente constante de la eternidad, aplacan los nervios de los ambiciosos, disipan las preocupaciones e invitan al sueño a los impacientes. ${ }^{47}$

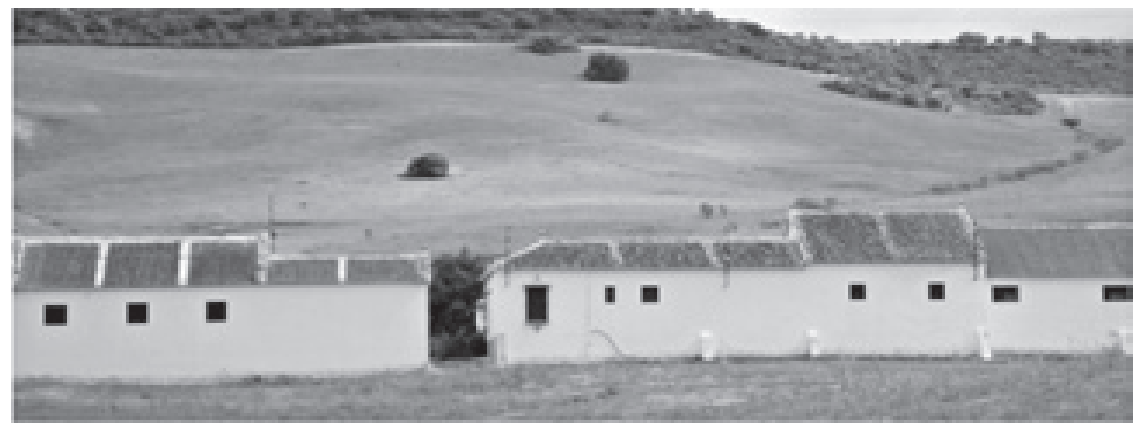

Imagen 9

Las ricas tonalidades cromáticas de las tierras del alto Guadaíra, potenciadas por el blanco de la cal en las instalaciones agrícolas y termales, los tonos verdes de la vegetación autóctona recuperada, de las huertas y de las zonas de cultivo, de la ribera del río y de los nuevos jardines, los grises de la

45 AZORÍN. Veraneo sentimental, p.134

46 MARTínEZ, Maria Azucena San Pedro. El balneario de Puente Viesgo, 1796-1936: el turismo balneario de interior en Cantabria. Génesis, esplendor y decadencia de un espacio de ocio. Santander: Universidad de Cantabria/ Fundación Marcelino Botín, 1993, p.146.

47 Palabras del marqués de Myra de Lyria en el prólogo del libro del VILLAR, Dr. Anselmo Albano. Caldas de Bohí: Anécdotas de mi vida balnearia. 2ªed. Sabadell: Farrús Folguera industrias gráficas, 1979. 
caliza de la sierra de Pozo Amargo, las láminas azules de agua que surgirán con las nuevas instalaciones termales, contribuirán a un incremento cromático de la belleza del lugar y de su capacidad de transmitir bienestar no sólo por la mencionada variedad de colores, sino también por la variedad de las formas y por el modelo o determinante cultural que tiene un paisaje como el de Pozo Amargo que puede identificarse plenamente con el modelo agropastoril europeo que ha ido elaborándose históricamente, a lo largo del tiempo. ${ }^{48}$

La zona del alto Guadaíra tiene también unos altos valores históricos, dado su carácter fronterizo, que le dieron relevancia en la época de la reconquista (banda morisca), en las guerras carlistas y en la época del bandidaje y contrabando decimonónicos. Los valores arqueológicos son también destacables ${ }^{49}$ y abundantes aunque muy poco estudiados hasta el momento. En el terreno del patrimonio cultural, etnográfico y arquitectónico ${ }^{50}$ destaca la proximidad de unas salinas todavía en uso, del propio pobladobalneario y de no pocas construcciones rurales que se insertan adecuadamente en su entorno paisajístico. ${ }^{51}$ La recuperación de toda esta identidad local y territorial es un elemento irrenunciable en un proyecto como éste que pretende mejorar la calidad de vida de los habitantes de Pozo Amargo y de los ususarios del balneario, recuperar el sentido del bien común. Un lugar como Pozo Amargo está lejos de ser un espacio homogeneizador, arraiga en el territorio y favorece la afición al lugar, el cariño hacia él porque se enmarca en un territorio con fuerte personalidad.

Por ello, la actuación se desarrollará en toda una serie de frentes que pasamos a enumerar: la conservación de la calidad del agua del manantial y de su entorno, del patrimonio cultural asociado al balneario y al poblado, del medio natural incluido en el perímetro de protección y cuenca de visibilidad, y del patrimonio histórico-arqueológico. Asimismo, incluye el desarrollo de actuaciones de uso público, un fomento de la participación social, ${ }^{52}$ la reactivación de sectores artesanales, un plan de divulgación y

48 LUGINBÜHL, Yves: Paisatge i benestar individual i social, p.26-29.

49 Un ejemplo magnífico de villa termal con yacimientos arqueológicos próximos es la de Puente Viesgo, Cantabria, con las cuevas del Castillo. Estos yacimientos fueron un recurso complementario a la actividad balnearia sobre todo desde los años cuarenta del s. XX.

50 GIL, José Antonio Ruiz y LÓPEZ, José María Gutiérrez. Territorio y poblamiento protohistórico en la sierra de Pozo Amargo (Puerto Serrano, Cádiz). Mauror, Morón de la Frontera, n.4, p.3-13, julio de 1997; Estudios geográficos históricos del antiguo territorio histórico moronés. Subprograma V. Inventario de los elementos culturales. Una aproximación al utillaje de los molinos del territorio antiguomoronés. Las culturas indígenas prerromanas y romanas I. Mauror, Morón de la Frontera, n.2, p.143-152, julio de 1996; PACHECO, Francisco Giles; PÉREZ, A. Santiago; ALMONTE, E. Mata; RODRíGUEZ, L. Aguilera y LÓPEZ, J. M. Gutiérrez. El Paleolítico de la cuenca media del Guadalete en el tramo Cádiz-Sevilla (Villamartín, Montellano y Puerto Serrano), Mauror. Morón de la Frontera, n.7, p.55-69, primer semestre de 1999. En particular debe verse el monográfico que dedicó Mauror en su número 16, segundo semestre de 2006, con interesantes artículos sobre el patrimonio cultural del entorno de Morón, incluyendo el paisaje urbano, el patrimonio y la arquitectura rural, las caleras, etc.

51 TORREJÓN, Guillermo Pavón y GARCÍA, Fernando Quiles. Arquitectura rural en Morón de la Frontera. Mauror, Morón de la Frontera, n.16, p.145-152, segundo semestre del 2006; CALA, Juan Pablo Morilla. De la choza al cortijo. Lo rural y más bello de nuestro patrimonio. Mauror, Morón de la Frontera, n.16, p.153-177, segundo semestre del 2006.

52 En este sentido los proyectos paisajísticos deben contar con una participación social cada vez mayor. Contrastan estos proyectos participativos con la utopía urbana de la elite ilustrada que atisbó la necesidad de reformas en los balnearios españoles, aunque las posibilidades económicas del país no permitieran grandes avances en este 
seguimiento de la actuación y, por último, el desarrollo de normativas de ámbito supramunicipal y municipal que controlen los problemas derivados de la escasa relación institucional que existe hoy en día con Puerto Serrano. ${ }^{53}$

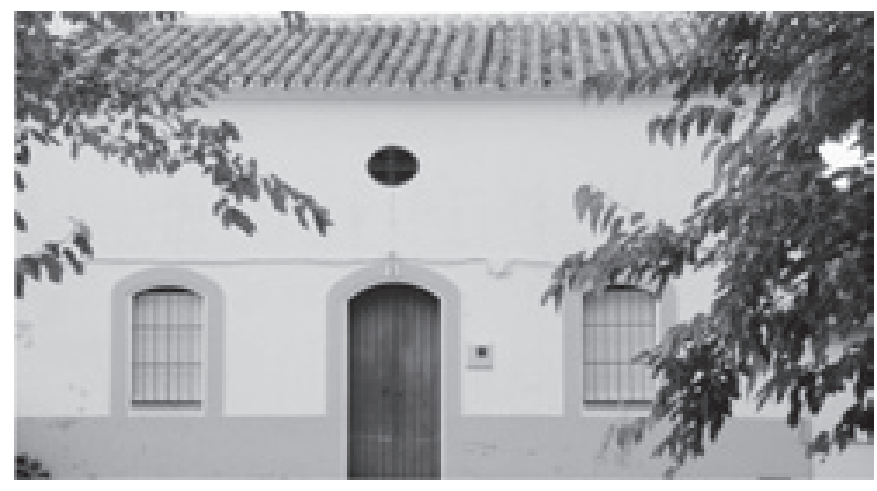

Imagen 10

Esta actuación sobre Pozo Amargo se explica y se justifica por el abandono del alto Guadaíra en las anteriores actuaciones sobre el río, circunstancia que podría explicarse por la baja presión urbanística que tiene la zona y también por la buena calidad que aún conservan sus aguas superficiales y sus acuíferos. ${ }^{54}$ Dentro del contexto general de una cuenca marcada por la fuerte contaminación de su principal río cobra más relevancia si cabe la existencia del manantial de agua mineromedicinal y la necesidad de protección para evitar su deterioro o eventual pérdida. La actuación paisajística y ambiental en Pozo Amargo puede resolver el problema de aguas negras que aún le caracteriza y puede abrir el debate sobre las posibilidades de un mayor uso de las aguas subterráneas de la cuenca para uso humano, algo que implicaría necesariamente una mayor atención sobre su calidad.

La actuación tiene interesantes potencialidades respecto al paisaje, debiendo paliar la intensa erosión que sufren las colinas tras el desmonte ocasionado por la explotación inadecuada del olivar y del cereal y mejorar las vistas del entorno del balneario para que redunde todo ello en una mejor acogida de la instalación balnearia y pueda consolidar así la oferta termal

terreno. No obstante, con la llustración se prepara el terreno para que se acometan posteriormente las reformas de balnearios como Trillo, Archena, Caldas de Besaya, Solán de Cabras, La Isabela, Caldas de Oviedo... en ellas trabajaron ya arquitectos destacados como Ventura Rodríguez, López Aguado o Mas i Font. Hoy en día también se ejecutan no pocos proyectos que carecen de conexión con la cultura del territorio en el que se ubican y que favorece la desconexión entre villa termal y explotación termal, como ha ocurrido en Carratraca, Málaga. Lo sostenible nos lleva sin duda a un modelo participativo.

53 Esto ya ha facilitado la aparición en el poblado de ciertos desmanes urbanísticos que han alterado su inicial estructura y fisonomía urbanística.

54 La zona cuenta con disponibilidad de agua subterránea procedente del acuífero de Pozo Amargo, del cual se abastece la población en la actualidad. Además, el propio manantial de agua mineromedicinal aporta un caudal de 8.000 litros/hora que puede utilizarse para otros usos en caso de necesidad. 
en Andalucía occidental, hoy en día apenas existente. A todos nos consta que otras actuaciones anteriores en el Guadaíra (el Programa Coordinado para el Saneamiento y la Recuperación Integral del Río Guadaíra, 1996, el llamado Guadaíra Verde) han permitido recuperar el rico patrimonio hidrológico (natural, histórico y cultural) de los molinos harineros de Alcalá, enriqueciendo el paisaje hidráulico de la cuenca pero también es muy evidente que no se ha planteado o no se ha concretado aún la recuperación de dos actividades tradicionales que además de incrementar la riqueza paisajística de la cuenca pueden tener incluso viabilidad económica en el entorno de Pozo Amargo: la propia explotación balnearia y las salinas que ya hemos venido mencionando a lo largo de este trabajo. ${ }^{55}$ En este sentido, la recuperación del poblado y del balneario de Pozo Amargo, la protección de la arquitectura rural y el plan de ordenación y gestión paisajística de su entorno debe posibilitar la diversificación económica de la zona y reactivarla sobre la base de la recuperación ambiental, resaltando de paso el papel histórico de esta zona de frontera entre el valle del Guadalquivir y el del Guadalete. ${ }^{56} \mathrm{~A}$ pesar de las dificultades que entraña romper esta tendencia al olvido de los problemas ambientales, culturales y socioeconómicos del alto Guadaíra en la administración autonómica, y las dificultades que implica poner en marcha un proyecto terma ${ }^{57}$ por los diferentes criterios que existen en materia sanitaria, patrimonial, etc. en las diferentes normativas estatales, autonómicas o locales, lo que pretendemos hacer en Pozo Amargo es recuperar la aldea termal y que esto nos permita conectar con la tradición que ha tenido la cuenca de aportar agua de calidad a la ciudad de Sevilla, muy en sintonía con la dignificación que supone para una población como la de Pozo Amargo el tener aguas de calidad, algo así como lo que está ocurriendo en la ciudad gallega de Ourense, ${ }^{58}$ nacida en torno a los manantiales prerromanos de As Burgas y que recientemente está apostando de forma decidida por la incorporación de esta tradición termal como elemento que defina a la ciudad. Algo parecido también a lo que recientemente ocurrió en la ciudad inglesa de Bath, identificada con la mejor tradición termal europea pero que no tenía hasta hace bien poco balneario en uso. Su recuperación no fue algo baladí, en ello iba a encontrar

55 A estas actividades hay que añadir la fabricación tradicional de cal, que actualmente busca encontrar un hueco en el mercado artesanal de dicho producto y que puede desempeñar un papel clave en el proceso de recuperación de las instalaciones como producto artesano de calidad. LOBO, Juan Antonio Carrillo. La cal de Morón. Sevilla: Asociación Cultural Hornos de la Cal de Morón, 2005.

56 Esto favorecía el intercambio de materias primas con ambas zonas aunque el poder de atracción de la gran ciudad comercial del valle del Guadalquivir que era Sevilla hacía mucho más fácil los intercambios con ella. ESTÉVEZ, Juan Clemente Rodríguez. Piedras de Morón para la catedral de Sevilla. Mauror, Morón de la Frontera, n.5, p.9-16, enero de 1998.

57 Intervención de Miguel Mirones en el Congreso Internacional de Turismo Termal, Ourense, 2-6 de marzo de 2011. Mirones, quien ocupa actualmente la presidencia de la Asociación Nacional de Balnearios (ANBAL), resaltó la necesidad que había de que hubiera una mayor transversalidad en las normativas.

58 Intervenciones de Francisco Rodríguez Fernández, alcalde del ayuntamiento de Ourense, y de José Luis Baltar Pumar, presidente de la Diputación Provincial de Ourense, en el Congreso Internacional de Turismo Termal, Ourense, 2-6 de marzo, 2011. 
la ciudad su esencia pues, como sabemos, en las villas termales el agua es la que determina su peculiar personalidad.

¿Podemos incorporar a Pozo Amargo en esa larga tradición que conecta el Guadaíra a la ciudad de Sevilla? Pensamos que sí, incorporando el tratamiento paisajístico de la aldea, la recuperación ambiental de su entorno, además de otros criterios indispensables hoy en día en este tipo de instalaciones como es la profesionalización, la formación, la introducción de criterios de calidad, ${ }^{59}$ atención personalizada e innovación en unas instalaciones modernas, bien organizadas y gestionadas, permitiendo que la riqueza natural que supone la existencia de aguas mineromedicinales, combinada con la paisajística, aporten a la zona una posibilidad de desarrollo turístico que iría acompañado por una gestión ambiental, paisajística, del patrimonio histórico-artístico y etnográfico, que deberían conseguir certificaciones de sostenibilidad del tipo Carbono Neutral, Sostenibilidad Turística, Luxury Eco Certification Standars, Green World Award.

Claro está que se intuye como muy necesaria la implicación y el apoyo institucional en un proyecto de estas características, dada su complejidad, pero también la iniciativa privada puede tener su espacio dado que la explotación termal puede tener viabilidad como tal. Muy recientemente, la aprobación por el Consejo de Ministros - el 4 de junio de 2010 - del Programa de Desarrollo Rural Sostenible 2010-2014 permitió incluir a los balnearios en este Programa ${ }^{60}$ Esta circunstancia abre un interesante camino para financiar todas aquellas acciones relacionadas con la calidad, la protección y puesta en valor de los recursos hidrominerales y su integración en el entorno natural y paisajístico, así como en el entramado empresarial y social de cada territorio. Es por ello que una propuesta como la que iniciamos desde este trabajo puede encontrar cabida en el Plan de Zona Rural que se prepare, concretando así la idea de que el termalismo puede ser un sector estratégico para el desarrollo territorial sostenible de las zonas rurales en las que haya recursos termales y que la vertiente paisajística puede aportar muchos elementos de mejora al proyecto concreto que se articule.

Nuestro proyecto holístico tiene pleno sentido en un momento en el que el sector termal está superando el concepto tradicional del balneario sólo como centro de salud. Hoy en día el balneario se abre - aunque en cierta forma siempre estuvo abierto - a productos diferentes. Esto influye a nivel paisajístico y ambiental por lo que un proyecto de intervención en Pozo Amargo tiene pleno sentido: el incremento del nivel cultural y económico de

59 Habría la posibilidad de incorporar esta experiencia termal en el alto Guadaíra como una experiencia pionera, que supondría introducir criterios paisajísticos en los estándares internacionales de calidad en explotaciones termales y terapéuticas (Q, ISO, EUROPESPA, etc.).

60 Véanse las alegaciones presentadas por el Observatorio del Termalismo a la versión preliminar del Programa de Desarrollo Rural Sostenible gracias a las que se pudo incluir al Termalismo y al Turismo termal en dicho Programa. Las alegaciones están fechadas en Alhama de Granada el 4 de diciembre de 2009 y resaltan la sostenibilidad de la explotación del recurso termal y su capacidad de generar empleo en el medio rural. 
los usuarios de los balnearios permite dotar de sentido a una intervención que también contempla en la actuación recuperar el patrimonio histórico y arqueológico del entorno. Las zonas bien conservadas de los alrededores del balnerio y las zonas a intervenir, tanto en el río como en zonas de cultivo cerealístico que han comido terreno al monte mediterráneo, deben permitir recuperar la vegetación autóctona y las tradicionales zonas de huerta que debieron rodear al establecimiento termal en un pasado no muy lejano. La posibilidad de que el usuario pueda también intervenir en este plan de recuperación ambiental cobra pleno sentido en un momento en el que un procentaje cada vez mayor de los usuarios de este tipo de instalaciones desea un ocio activo que le permita intervenir en su entorno y en cierta forma crear un paisaje en el que sentirse implicado.

Acabamos como partimos, hablando de la belleza del paisaje de Pozo Amargo, creemos en ella y somos conscientes también de las posibles repercusiones negativas de una actuación poco respetuosa con el lugar. Por ello se hace obligatorio recuperar las microhistorias escondidas en la aldea, recuperar a los anónimos creadores del paisaje de Pozo Amargo, asistir a los procesos y fases de su decadencia para no caer en propuestas alejadas de sus raíces históricas. Conocer cómo se forjaron en sus casas, en la plaza de la villa termal y en su pequeña iglesia las raíces afectivas de sus gentes, el sentimiento de pertenencia y cómo este sentimiento ha ido evolucionando a lo largo del tiempo. En Pozo Amargo todavía podemos encontrar algo de lo que fue, podemos reconocernos en él. Para ello nos falta recuperar el balneario, su función como poblado, su razón de ser. Un proceso de búsqueda de identidad como fue el protagonizado recientemente por Bath, como lo que pretenden tantas villas termales que desean recuperar su personalidad. Esta dignificación de Pozo Amargo sobre bases de sustentabilidad está en la base de nuestra propuesta, al igual que recuperar el sentido de pertenencia a este rincón del alto Guadaíra, contando para ello con las muy activas asociaciones de la cuenca. Si conseguimos reparar sentimentalmente estos paisajes habrá una parte del camino andada. Si conseguimos que la calidad visual, la belleza en definitiva, no se vea como un accesorio sin importancia sino como un valor esencial de las relaciones del hombre con su paisaje habremos dado un paso adelante. ${ }^{61}$

61 Cómo no recordar aquí la genial escena de Akira Kurosawa en su largometraje "Los sueños", en la que los espíritus de los duraznos le recriminan al hijo de la familia que los ha cortado que ahora llore su ausencia. El hijo se justifica de que no llora por que le gustaran los duraznos y ahora no pudiera comerlos - pues los duraznos siempre se pueden comprar - sino porque la belleza de un huerto entero de durazneros en flor jamás se puede comprar (Akira Kurosawa's dreams, 1990, segunda historia: "El huerto de los duraznos"). El episodio ejemplifica como pocos, visual y musicalmente, cómo un trauma paisajístico puede traducirse en un trauma psicológico, de cómo la depresión motivada por un trauma paisajístico puede aumentar la vulnerabilidad psicológica humana, de la importancia que tiene la belleza paisajística en lo que hemos dado en denominar "calidad de vida". VALLERANI Francesco. La pèrdua traumàtica del sentit del Iloc: degradació del paisatge i patologies depressives. Paisatge i salud. Barcelona-Olot: Observatori del Paisatge-Generalitat de Catalunya, 2011, p.75. O como dice el anciano del sueño "La villa de los molinos de agua": "Las cosas más importantes para el ser humano son el aire puro y el agua limpia, y los árboles y hierbas que los producen" (Akira Kurosawa's dreams, 1990). 